\title{
The preferential location of the human $Y$ chromosome in somatic metaphase. I. Influence of $\mathrm{Y}$ polymorphism
}

\author{
Paul Genest, Fernande B. Genest \\ and Denyse Genest
}

Laboratoire de Cytogénétique, Département de Pathologie, Faculté de Médecine, Université Laval, Québec, Q.C., G1K 7P4, Canada.

The location of the $\mathrm{Y}$ chromosome in metaphase figures was studied, with respect to its polymorphism, on 700 micrographs from blood lymphocyte cultures from 70 normal male members of seven Candian family lines whose polymorphic $Y$ chromosomes were inherited in a patrilinear fashion from seventeenth-century French ancestors. Three of these family lines were carriers of a long $Y$ chromosome, two a small one, one had an average length $Y$ and a seventh one had a satellited $Y$ marker. The $Y$ chromosome was peripheral in 75 to 90 per cent of the metaphase plates from each individual investigated. The long $Y$ markers were more peripheral than the small ones while the average length $Y$ chromosome had an intermediate position, whereas the satellited $Y$ chromosome was located within the small group. The difference between the location of the long and the small $Y$ chromosomes was highly significant. It is hypothesised that a heteromorphic Y might affect the nonrandom orientation of metaphasic chromosomes and favour meiotic nondisjunction and aneuploidy.

\section{INTRODUCTION}

While the relative position of chromosomes in metaphase spreads should tend to be nonrandom, there is some disagreement about the actual metaphysic location of the Y chromsome. These conflicting views may be due to differences in methodology, variability in the definition of peripheral location, number of individuals or cells examined, and the genetic background of the subjects investigated. In order to obtain reliable results in the study of $Y$ chromsome position in metaphase, Verma et al., (1984) used the race and length heteromorphism criteria. In this report we examined the location of the $\mathrm{Y}$ chromsome in metaphase figures from normal male members of family lines different from each other by their heteromorphic Y chromosomes.

\section{MATERIAL AND METHODS}

Chromosome analysis of peripheral blood lymphocyte cultures was done by routine methods and $\mathrm{Y}$ chromosome identification was ascertained by the Q- and C-banding techniques. The length of the $\mathrm{Y}$ was determined by the $\mathrm{Y} / \mathrm{F}$ index ratio following measurements with a curvimeter on projected photomicrographs $(\times 25,000)$ of the $Y$ and the F-group chromosomes of 10 metaphases from each of five individuals randomly chosen from a given family line. Satellite appendices of Yqs were not taken into account. The location of the $Y$ chromsome on metaphase figures was performed by the method and peripheral definition of Kowalski et al., (1978), directly on enlarged micrographs $(\times 2,800)$ of 10 lymphocyte 46 -chromosome metaphases of each of 10 normal males from each of the seven (7) family lines. Cells were randomly chosen providing that they were euploid and the $Y$ chromosome could be identified easily on chromosome preparations stained by the conventional Giemsa technique in order to have welldefined centromeres. To evaluate the position of the $\mathrm{Y}$ chromosome a reference line was drawn connecting the centromere of chromosomes 1 . These were chosen because they were easily identified. Lines parallel and perpendicular to the reference line were then drawn through the centromeres of the most peripheral chromosomes with respect to the starting point. A rectangle (or square) was then formed in which all the chromosomes in the spread were included. The centre of the metaphase was therefore at the intersection of two diagonals 
crossing the rectangle. To determine the section in which the $\mathrm{Y}$ chromsome was located, another line was drawn between the centre of the metaphase and the centromere of the $\mathrm{Y}$. Two zones were then formed by drawing lines connecting the centromere of the $\mathrm{Y}$ chromosome or the centre of the metaphase to the boundary of the rectangle; the inner zone with the $\mathrm{Y}$ at right angle, and the outer zone with the centre of the spread at right angle. The two lines of the inner zone, perpendicular to the rectangle, were identified by the symbols $D^{1}$ and $D^{2}$ respectively, and those of the outer zone were $D^{3}$ and $D^{4}$. The position of the $Y$ chromsome was computed by the formula:

$$
\frac{D^{1} \times D^{2}}{D^{3} \times D^{4}}=P \text {. }
$$

Y chromosome was said to be peripheral if $P<$ $0 \cdot 500$. Although the basics of this geometric technique are arbitrary, it can be applied to any kind of metaphase figures, whether círcular or not. The $\chi^{2}$ test with Yates' correction was employed to analyse the differences between the spatial position of the long and that of the small $\mathrm{Y}$ chromosomes.

\section{RESULTS}

The length of the $\mathrm{Y}$ chromosome was measured on 350 metaphase spreads and results are classified in table 1. One family line has a $\mathrm{Y}$ of average size, two have a small one, three have a long $Y$, and the seventh family line is a carrier of a long satellited $\mathrm{Y}$ chromosome. The $\mathrm{Y}$ was found to be at periphery of most of the metaphase plates of each of the 70 males examined, and its peripheral location varied from 70 to 90 per cent of the cells depending on its length or structural rearrangement (table 2). The length of the Y chromosome had a distinct influence on its spatial position. The
Table 1 Types of $\mathrm{Y}$ chromosome and $\mathrm{Y} / \mathrm{F}$ index ratio found in normal male individuals from the seven (7) family lines investigated

\begin{tabular}{lll}
\hline Family line & $\begin{array}{l}\text { Y chromosome } \\
\text { polymorphism }\end{array}$ & Y/F index* \\
\hline $\mathrm{Be}$ & normal Y & $0 \cdot 829 \pm 0 \cdot 007$ \\
$\mathrm{Ce}$ & small Y & $0 \cdot 623 \pm 0 \cdot 011$ \\
$\mathrm{Bn}$ & small Y & $0 \cdot 577 \pm 0 \cdot 016$ \\
$\mathrm{Br}$ & long Y & $1 \cdot 108 \pm 0 \cdot 004$ \\
$\mathrm{Gu}$ & long Y & $1 \cdot 146 \pm 0 \cdot 012$ \\
$\mathrm{Ry}$ & long Y & $1 \cdot 101 \pm 0 \cdot 012$ \\
$\mathrm{RD}$ & satellited Y & $1.095 \pm 0.023$ \\
\hline
\end{tabular}

* $\mathrm{Y} / \mathrm{FF}$ index $=$ total length of the $\mathrm{Y}$ chromosome/average length of the F-group chromosomes.

three long $\mathrm{Y}$ chromosomes were more peripheral than the small ones, whereas the average length $Y$ had an intermediate position while the satellited $Y$ was located within the small $Y$ group. The $\chi^{2}$ analysis demonstrated significantly that a smaller Y chromosome is more likely to be displaced from the periphery of the metaphase (table 3 ).

\section{DISCUSSION}

The investigation on the location of the $\mathrm{Y}$ chromosome in 700 metaphase figures from 70 carriers of polymorphic inherited $Y$ chromosomes confirms the hypothesis that the $\mathrm{Y}$ has a tendency to have a peripheral position in metaphase spreads of human lymphocyte cultures. Along with the peripheral location of the $\mathrm{Y}$ chromosome, our results suggest that the length of the $Y$ influences its spatial position. A long $Y$ has a tendency to be more peripheral, and a small one less peripheral while an average length $Y$ chromosome is located at equidistance from the heteromorphic $Y$ chromosomes. Data on the position analysis of the metaphase chromsomes provide evidence that

Table 2 Location of the Y chromosome in metaphase cells in normal individuals from seven (7) family lines with Y polymorphism

\begin{tabular}{lllccc}
\hline $\begin{array}{l}\text { Family } \\
\text { line }\end{array}$ & Karyotype & $\begin{array}{l}\text { Mean value } \\
\text { of peripheral } Y^{*}\end{array}$ & Peripheral Y & Non-peripheral Y & Cells \\
\hline $\mathrm{Be}$ & $46, \mathrm{XY}$ & $0 \cdot 260 \pm 0.025$ & 87 & 13 & 100 \\
$\mathrm{Ce}$ & $46, \mathrm{XYQ}-$ & $0 \cdot 289 \pm 0 \cdot 012$ & 79 & 21 & 100 \\
$\mathrm{Bn}$ & $46, \mathrm{XYq}-$ & $0 \cdot 327 \pm 0 \cdot 024$ & 75 & 25 & 100 \\
$\mathrm{Br}$ & $46, \mathrm{XTq}+$ & $0 \cdot 232 \pm 0 \cdot 018$ & 90 & 10 & 100 \\
$\mathrm{Gu}$ & $46, \mathrm{XYq+}$ & $0 \cdot 228 \pm 0 \cdot 011$ & 86 & 12 & 100 \\
$\mathrm{Ry}$ & $46, \mathrm{XYq}+$ & $0 \cdot 245 \pm 0 \cdot 022$ & 88 & 20 & 100 \\
$\mathrm{RD}$ & $46, \mathrm{XYqs}$ & $0 \cdot 290 \pm 0.025$ & 80 & 20 \\
\hline
\end{tabular}

\footnotetext{
* $\mathrm{Y}$ chromosome is peripheral (P) if $\mathrm{P}$ index is $<0.500$ (see text for explanation)
} 
Table 3 Test* of the hypothesis that the Y chromosome length influences its location in metaphase spreads $(\alpha=0.05)$

\begin{tabular}{lrrr}
\hline Location & $Y q+$ & $Y q-$ & \multicolumn{1}{c}{ Total } \\
\hline Peripheral $\dagger$ & $264(88)$ & $154(77)$ & $418(83 \cdot 6)$ \\
Non-peripheral & $36(12)$ & $46(23)$ & $82(16 \cdot 4)$ \\
$\quad$ Total & $300(100)$ & $200(100)$ & $500(100)$ \\
\hline
\end{tabular}

$\chi^{2}=9 \cdot 803 . P($ bilateral $)=0.0017$.

* Schlesselman, J. (1982) Case-Control Studies. Oxford Univ. Press, New York, p. 175.

$\dagger$ See text for explanation

Data in parentheses are percentages

genetically less active heterochromatin is accumulated at the periphery of the nucleus (Hens et al., 1982). Although small chromsomes are prone to lie nearer the centre of the mitosis, the Y chromosome is more peripheral than expected (Wollenberg et al., 1982).

Although the satellited $\mathrm{Y}$ that was analysed is longer than average it was found to lie less peripherally than the three long ones. Because it is a satellite carrier, it may have been attracted by acrocentric chromosomes. According to Barton et al., 1965; Galperin 1968; Kirsch-Volders et al., 1977 , acrocentrics show a concordant central position probably due to their participation in the nucleolus organisation.

Besides the deviation of the satellited $\mathrm{Y}$ from its expected location at metaphase, the variation observed in the orientation of polymorphic $Y$ chromosomes may indicate that a heteromorphic $Y$ may have an influence on meiotic nondisjunction. Cases of trisomic 21 patients with a long Y chromosome along with their normal relatives have been reported (Bishop et al., 1962; Dekaban et al., 1963). Mattéi et al. (1979) stated that the incidence of trisomic 21 individuals in families with long $Y$ is greater than in the general population. Furthermore, Verma et al. (1982), investigating the length of the $\mathrm{Y}$ chromosome in 42 black patients with trisomy 21 , and a similar number of normal individuals, found that one-third of trisomy 21 cases had a small $Y$ chromosome. It is not irrational to hypothesise that there is a correlation between the effect of a polymorphic Y chromosome on its spatial position in the metaphase plate and an increase risk of its male carrier for aneuploidy.

Acknowledgements We are indebted to Dr Ronald Hancock for the revision of the manuscript.

\section{REFERENCES}

BARTON, D. E., DAVID, F. N. AND MERRINGTON, M. 1965. The relative position of the chromsomes in the human cell in mitosis. Ann. Hum. Genet., 29, 139-146.

BISHOP, A., BLANK, C. E. AND HUNTER, H. 1962. Heritable variation in the length of the $\mathrm{Y}$ chromosome. Lancet, II, 18-19. DEKABAN, A. S., BENDER, M. A. AND ECONOMOS, G. E. 1963. Chromosome studies in mongoloids and their families. Cytogenetics, 2, 61-75.

GALPERIN, H. 1968. Etude de la distribution générale des 46 chromosomes dans les cellules humaines en métaphase. Humangenetik, 6, 118-130.

HENS, L., KIRSCH-VOLDERS, M., VERSCHAEVE, L. AND SUZANNE, C. 1982. The central localization of the small and early replication chromosomes in human diploid metaphase figures. Hum. Genet., 60, 249-256.

KIRSCH-VOLDERS, N., HENS, L., SUZANNE, C. AND GALPERIN-LEMAITRE, H. 1977. Stability of centromere-center distances in normal human metaphases. Cytogenet. Cell Genet., $18,61-74$.

KOWALSKI, C. J., NASJLETI, C. E. AND SCHMITT, B. 1978. On the peripheral location of the Y chromosome. Hum. Genet., 44, 123-135.

MATTEI, J. F., MATTEI, M. G., LUCAS, C. AND GIRAUD, F. 1979. Les anomalies de structure du chromosome Y. J. Génét. hum., 27, 53-66.

VERMA, R. S., HUQ, A., MADAHAR, C., QAZI, Q. AND DOSIK, H. 1982. Higher incidence of small $Y$ chromosome in humans with trisomy 21 (Down syndrome). Pediat. Res., 16, 769-770. VERMA, R. S., RODRIGUEZ, J., SHAH, J. V. AND DOSIK, H. Peripheral location of the $\mathrm{Y}$ chromosome: relationship to race and length heteromorphism. Heredity, 52, 227-234.

WOLLENBERG, C., KIEFABER, M. P. AND ZANG, K. D. 1982. Quantitative studies on the arrangement of human metaphase chromosomes. VIII. Localization of homologous chromosomes. Hum. Genet., 60, 239-248. 